\title{
Clostridium difficile in clinical practice: Increasing rates, more virulent organisms and new therapies on the horizon
}

\author{
Thomas J Louie MD FRCPC
}

\begin{abstract}
TJ Louie. Clostridium difficile in clinical practice: Increasing rates, more virulent organisms and new therapies on the horizon. Can J Infect Dis Med Microbiol 2006;17(Suppl B):19B-24B.
\end{abstract}

Clostridium difficile-associated diarrhea has recently come under increasing scrutiny because of outbreaks of disease in eastern Canada in association with a hypervirulent ribotype 027 (NAP1) strain. Hospitals in the United States, the United Kingdom and Europe have been affected as well. Epidemiological studies are underway to determine the presence of the more virulent strain of $\mathrm{C}$ difficile in hospitals across Canada. Because this strain is highly quinolone resistant, it is suspected that overuse of that class of antimicrobial agent may be a selection factor for this strain. Although $\mathrm{C}$ difficile-associated diarrhea is usually considered a nosocomial infection, approximately one-quarter of cases occur in the community. Recurrence following successful resolution of diarrhea occurs in one in five patients treated with metronidazole or vancomycin; relapse is more common in patients needing retreatment. New therapies that may have equivalent or higher response rates and lower recurrence rates are being investigated. It is hoped that these new treatments will be a substantial improvement over current therapies. In the interim, prudent antimicrobial use and attention to infection control practices are the main preventive strategies. Prompt testing for $\mathrm{C}$ difficile toxin in patients with diarrhea after antibiotic exposure, discontinuation of unnecessary antibiotic therapy and rapid initiation of treatment should minimize complications. With the appearance of more toxigenic strains of $\mathrm{C}$ difficile, careful monitoring of patients to detect suboptimal clinical response is necessary.

Key Words: Clostridium difficile; New therapies; Virulence

$\mathrm{O}$ utbreaks of Clostridium difficile-associated diarrhea (CDAD) in Canada have called attention to this important adverse outcome of antibiotic prescribing. Yet, beyond diagnosis by testing for $\mathrm{C}$ difficile toxins and prescribing of metronidazole or vancomycin as treatment, health care providers are aware that there are few other proven treatment options for nonresponders or patients with recurrent illness. The present paper provides a summary of the current issues.

\section{CHANGING EPIDEMIOLOGY: INCREASING INCIDENCE OF DISEASE AND OUTBREAKS WITH INCREASED VIRULENCE}

CDAD is endemic in every community as a by-product of antibiotic prescribing. Physicians in office practice sporadically manage cases, and those working in hospitals are cognizant of the institutional endemicity of $\mathrm{C}$ difficile. A recent Swedish

\section{Le Clostridium difficile en pratique clinique : Des taux croissants, des organismes plus virulents et de nouvelles thérapies à l'horizon}

\begin{abstract}
La diarrhée associée au Clostridium difficile a récemment fait l'objet d'une surveillance étroite en raison de flambées de la maladie dans l'est du Canada, associées à une souche hypervirulente de ribotype 027 (NAP1). Des hôpitaux des États-Unis, du Royaume-Uni et de l'Europe ont également été touchés. Des études épidémiologiques sont en cours pour déterminer la présence de la forme la plus virulente de $\mathrm{C}$ difficile dans les hôpitaux du Canada. Puisque cette souche est très résistante à la quinolone, on présume que la surutilisation de cette classe d'antimicrobiens pourrait être un facteur de sélection de la souche. Bien que la diarrhée associée au $\mathrm{C}$ difficile soit généralement considérée comme une infection nosocomiale, environ le quart des cas se déclarent dans la collectivité. Un patient sur cinq qui est traité au métronidazole ou à la vancomycine souffre d'une récurrence après la résolution de la diarrhée, et les rechutes sont plus fréquentes chez les patients qui ont besoin d'une reprise du traitement. De nouveaux traitements qui pourraient s'associer à des taux de réponse équivalents ou plus élevés sont en cours d'étude. On espère qu'ils apporteront des améliorations significatives par rapport aux anciens traitements. Entre-temps, l'utilisation prudente d'antimicrobiens et une attention étroite prêtée aux pratiques de contrôle des infections représentent les principales stratégies de prévention. Un test de dépistage rapide de la toxine $\mathrm{C}$ difficile chez les patients atteints de diarrhée après une exposition aux antibiotiques, l'abandon de l'antibiothérapie inutile et l'instauration rapide du traitement devraient réduire les complications au minimum. Étant donné l'apparition de souches plus toxigènes de $\mathrm{C}$ difficile, un monitorage attentif des patients s'impose en vue de déceler les réponses cliniques sous-optimales.
\end{abstract}

study (1) determined that the incidence of disease is 1300 -fold higher in medical and surgical wards than in the community. Taking Calgary, Alberta, as an average Canadian city, with a service population of approximately one million, approximately 600 persons are diagnosed with CDAD each year in the absence of an outbreak of the disease. In general, two-thirds of cases are hospital-acquired and the remainder are diagnosed in physicians' offices. In hospitals not experiencing an outbreak, a case rate of approximately two in 1000 admissions or three in 10,000 patient-days has been observed. It is estimated that there are 15,000 to 19,000 cases per year in Canada. The actual number of persons affected in Canada each year is not known because CDAD is not an infection reportable to public health authorities in most provinces. A Canada-wide survey of CDAD in 1997 showed that there was a 1\% likelihood of fatality from infection (2). Rates of illness appear to be rising in the

Departments of Medicine, and Microbiology and Infectious Diseases, University of Calgary, and Infection Prevention and Control Program, Calgary Health Region, Calgary, Alberta

Correspondence and reprints: Dr Thomas J Louie, Departments of Medicine, and Microbiology and Infectious Diseases, University of Calgary, 2500 University Drive Northwest, Calgary, Alberta T2N 1N4. Telephone 403-944-4766, fax 403-944-2484, e-mail louie@ucalgary.ca 
absence of defined outbreaks. The Centers for Disease Control and Prevention estimate that there are 178,000 cases per year in the United States, affecting one in 1700 persons per year - a case rate double that of a decade ago (3). The United Kingdom has tracked the annual incidence of CDAD for more than a decade and has documented a five- to sevenfold increase in case rates since the early 1990s. In 2004, 44,000 new cases were reported to the Health Protection Agency in the United Kingdom, double the number in 2001 (4). These rates appear to precede the emergence of the ribotype 027 organism as an outbreak strain.

Outbreaks of disease have resulted in case rates that are fiveto 10-fold higher. Most outbreaks investigated in the past decade have been proven to be clonal (ie, spread of a particular strain) (5). In Calgary in 2000 to 2001, during an outbreak involving a clindamycin-resistant clone (selected for by excessive clindamycin prescribing) that affected all three adult general hospitals, the peak case rate was sevenfold higher than before the outbreak. At that time, $77 \%$ of isolates were of one clone. Restriction of clindamycin use rapidly controlled the outbreak, and over the past four years, the prevalence of the outbreak strain has been markedly reduced (6). In 2002 to 2004, a multihospital outbreak in Quebec involving a single clone has been associated with case rates of 14 to 35 cases per 10,000 patientdays (7). A hypertoxigenic ribotype 027, toxinotype III, North American pulso-type clone (NAP1), which is closely related to strains previously known to be present in Europe, has accounted for the majority of strains in affected Quebec hospitals (8). This clone has an abnormal toxin repressor gene that causes it to make 16 to 20 times as much $\mathrm{C}$ difficile toxin $\mathrm{A}$ and $\mathrm{B}$ in vitro as do 'normal' strains, and produces toxin immediately in the log phase growth curve rather than later in the stationary phase, as has been the case in 'normal' strains (9). Infection has been associated with more fulminant disease, resulting in death rates more than three times higher than expected for matched patient control subjects in the elderly population (10). Concurrently, a number of American hospitals have been investigated for outbreaks involving the same or a similar clone (11). The outbreak strain is highly quinolone-resistant, and it is suspected that overuse of quinolones is a driving force behind these outbreaks. Ongoing investigations of outbreaks in Europe are supportive of the notion that quinolones as a class are a factor in selecting these outbreak strains (12).

Is the Quebec outbreak strain or similar strains present in other Canadian communities? A recently completed survey (13) of nosocomial CDAD cases involving 34 hospitals across Canada from November 2004 to May 2005, and which included culture confirmation of the pathogen, showed that this strain is present in seven provinces. This strain has been present in Calgary, without a defined outbreak, since 2001, and accounts for $16 \%$ of community strains and $2 \%$ to $5 \%$ of hospital strains (14). It appears that the presence of the strain does not mean that an outbreak is imminent, and that other factors or processes have allowed for the development of an outbreak.

Physicians need to be aware that outbreaks of infection are on the rise and the causes may be multifactorial. In addition to strain virulence, crowded hospitals with high occupancy, increased or continued antibiotic selection pressure, transmission-prone hospital environs, inadequate infection control conditions or practices, an increasing aged population with increased susceptibility to fulminant infection and possible cofactors such as widespread proton pump inhibitor use are suspected reasons for the increasing rates of infection (15-17).
Therefore, physicians need to prescribe antimicrobial agents sparingly and to maintain infection control practices (for all patients, not only for identified cases) because these two factors repeatedly emerge as successful control measures against CDAD. Improved infection control resources have halved the case rates of CDAD in Quebec. Additional measures are required in the face of rising case rates.

\section{DIAGNOSIS OF CDAD}

Detection of $\mathrm{C}$ difficile toxins is the main diagnostic end point. Patients who have diarrhea in association with prior or concurrent antibiotic exposure should be routinely screened for the presence of $\mathrm{C}$ difficile toxin in fecal samples. Generally, approximately $8 \%$ to $10 \%$ of submitted stool samples are found to be positive. Testing should be available on a daily basis with as short a turnaround time as is practicable. Enzyme immunoassays (EIAs) are the most commonly used tests in the clinical laboratory due to their low cost, ease of use, less than one-day turnaround times and high specificity. Because controlled studies have shown that EIA tests are $55 \%$ to $89 \%$ sensitive in detecting toxin (18-20), repeat tests should be ordered in highly suspected cases. The tissue culture toxin assay, long used as the reference standard, detects lower concentrations of toxin B, but is less commonly used now because of its higher cost and slower turnaround time. Endoscopy is occasionally required to confirm a diagnosis of presumed colitis in the face of negative test results (this is estimated to occur in about $2 \%$ of instances, so it is not rare). Culture for $\mathrm{C}$ difficile alone is not adequate for diagnosis because one-quarter of strains are nontoxigenic (and therefore not considered pathogenic). In addition to cytotoxicity testing, culture to recover $\mathrm{C}$ difficile with confirmation of toxigenicity has been found to increase the number of cases found by $15 \%$ to $77 \%(21,22)$, but this is not commonly done. In the event that test results are not to be available for $48 \mathrm{~h}$ to $72 \mathrm{~h}$, it is prudent to consider empirical therapy of florid cases (ie, known prevalence of CDAD on the ward; antibiotic exposure; older patients with comorbid conditions; or presence of diarrhea, fever or leukocytosis) that are clinically compatible with CDAD (23).

Once a case is diagnosed, it is not necessary to retest with additional EIA tests to guide further management. A common error on hospital wards is to order repeat EIA tests to determine when to discontinue isolation. Patients should remain in contact isolation with separate toilet facilities until diarrhea has resolved and the patient is proficient at maintaining bowel continence for approximately $48 \mathrm{~h}$. Despite a negative toxin test, stools of patients with CDAD continue to have infectious spores during and following therapy. Alternatively, firm stools may still yield a positive toxin test.

In patients who have recurrence of diarrhea following a successful response to initial therapy, the EIA toxin test may be negative initially, despite a clinical diagnosis of relapsed CDAD. The toxin test should be repeated and, in the absence of an alternative cause, treatment may be considered.

\section{IS IT NECESSARY TO TREAT ALL PATIENTS?}

With increased virulence and with the inability to determine which patients will abruptly deteriorate, there is now a movement to consider treating all patients. However, this may vary by hospital, region and clinical circumstance. If the patient is on the inducing antibiotic and it is not necessary to continue treatment, stopping antibiotic therapy is the first priority. 
Observational studies have shown that stopping the antibiotic leads to cessation of diarrhea in approximately $25 \%$ of patients within approximately four days. The Cochrane review of CDAD (24) also concludes that there is likely a selfresolution rate that needs to be considered in therapeutic trials. A common office practice scenario is the screening of patients who develop diarrhea following or during antibiotic therapy. The antibiotic is discontinued and a request for toxin testing is made. Depending on testing parameters, often $48 \mathrm{~h}$ to $72 \mathrm{~h}$ elapses before results are returned to the office. In these milder cases, an inquiry should be made regarding persistence of diarrhea. If patients have fewer than three bowel movements per day, and they are otherwise well, it is acceptable to observe them and provide follow-up care. This is because current therapies are likely to suppress the residual normal gut flora and may predispose patients to relapse. In the future, when therapies with a lesser likelihood of relapse become available, it may become more convenient to treat all patients.

\section{THERAPY}

Metronidazole $500 \mathrm{mg}$ three times daily or $250 \mathrm{mg}$ four times daily by mouth for 10 to 14 days remains the standard treatment for CDAD (Figure 1). During the outbreak in Quebec, vancomycin was preferentially used in some of the affected hospitals. Metronidazole works by being absorbed in the upper gastrointestinal tract, and is leached through the inflamed bowel mucosa into the intestinal lumen. Maximal concentrations of metronidazole are in the order of $7 \mu \mathrm{g} / \mathrm{mL}$ in fecal filtrates, and minimum inhibitory concentrations are usually $1 \mu \mathrm{g} / \mathrm{mL}$ or lower. Resistance to metronidazole is rarely observed. Nausea, abdominal cramps, altered taste and headache may occur in up to one-half of patients receiving metronidazole; however, only approximately $10 \%$ of patients require discontinuation of the drug. A higher than expected rate of relapse after metronidazole therapy were observed by physicians in Quebec during the recent outbreak (25).

Vancomycin $125 \mathrm{mg}$ four times daily for 10 days is also a standard regimen. Fewer than $10 \%$ of patients require a higher dose to attain a response. It was previously shown that patients randomly assigned to $125 \mathrm{mg}$ or $500 \mathrm{mg}$ four times daily did not have major differences in diarrhea resolution (26). Therefore, a higher dose of $250 \mathrm{mg}$ to $500 \mathrm{mg}$ four times daily should not be routinely used as the initial therapy. The failure to respond to the $125 \mathrm{mg}$ dose is unexplained because vancomycin concentrations in fecal filtrates with the standard dose are several hundredfold higher than the minimum inhibitory concentration of the pathogen $(1 \mu \mathrm{g} / \mathrm{mL}$ to $2 \mu \mathrm{g} / \mathrm{mL})$.

At present, cost differences and the higher likelihood of selection for vancomycin-resistant enterococci favour the use of metronidazole in routine clinical practice. Metronidazole should remain the first-line choice, with vancomycin as the alternative. The response to metronidazole or vancomycin is achieved in $4 \pm 2$ days in most patients, with the clinical impression that vancomycin works somewhat faster. It may take seven to nine days before diarrheal symptoms resolve in some patients. In the absence of worsening diarrhea, increased abdominal pain, fever and leukocytosis, these patients may be closely followed. Vancomycin $125 \mathrm{mg}$ capsules four times daily for 10 days costs approximately $\$ 300$. An increasingly common practice is the use of the intravenous form, given orally both in hospital practice and in an outpatient setting, provided that the pharmacy is willing to reconstitute the vancomycin. Less than $0.5 \%$ of vancomycin is absorbed. Vancomycin damages the

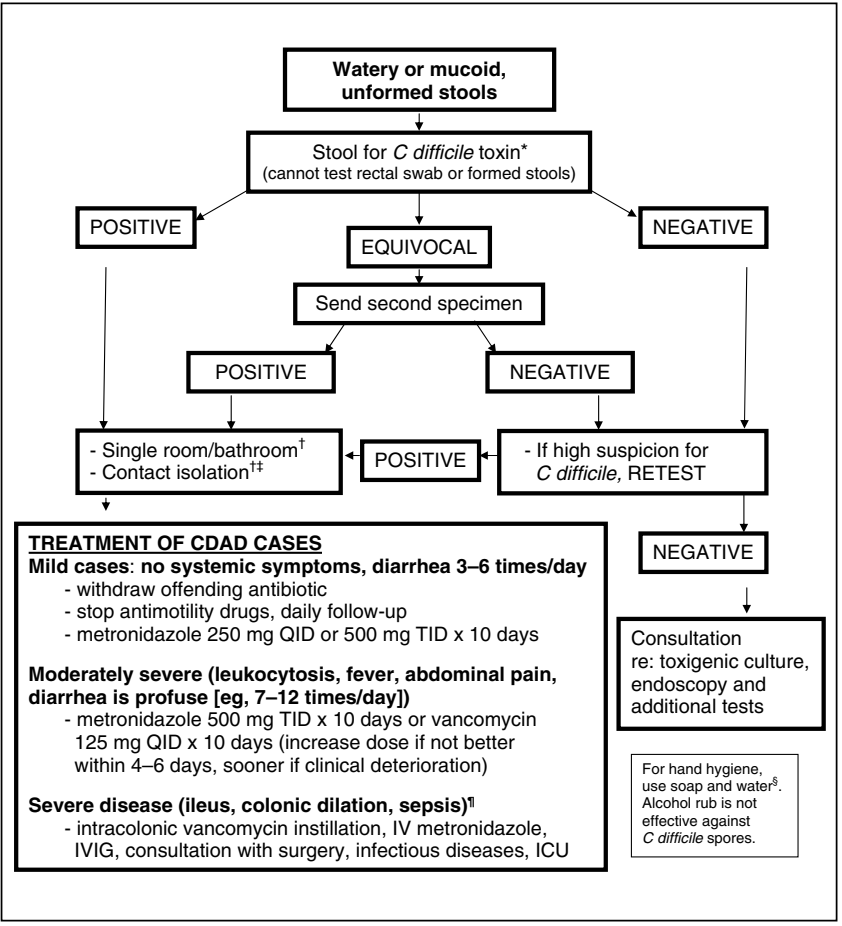

Figure 1) Management of adult patients with Clostridium difficileassociated diarrhea (CDAD). *Do not repeat stool tests once a patient has a positive $\mathrm{C}$ difficile stool toxin test unless the patient was successfully treated and subsequently has recurrent diarrhea (repeat stool testing is used to confirm that the relapsing diarrhea is due to C difficile [see $\$]$ ). Medical management is determined with the first positive test, and treatment is not altered with repeat positive tests. Discontinuation of isolation is based on cessation of diarrhea. A negative toxin is not required to discontinue precautions. ${ }^{\dagger}$ A private bathroom is preferred, if possible. After patient is transferred to a private room, the old room and old bathroom should undergo terminal cleaning with bleach or activated hydrogen peroxide agent. Commodes are potential vehicles for transmission and should not be shared between patients. FThe criteria for discontinuing isolation are as follows: patient is symptom free for $48 \mathrm{~h}$ and has had at least one normal or formed stool, and if the patient has underlying chronic diarrhea (for other reasons) or is given a bowel routine or treatment that causes loose frequent stools, it may be necessary to repeat toxin testing to decide whether the CDAD has resolved. ${ }^{\S}$ While recent studies have shown that alcohol-based hand rubs have not been associated with increased rates of $\mathrm{CDAD}$, handwashing with soap (or $2 \%$ chlorhexidine gluconate) and water is preferred. Hand hygiene before and after all patient contact as part of standard practice should be the 'culture' of physicians and other health care providers. For each proven case of nosocomial infection, there are several others that are undetected. IT The best treatments have not been well investigated in clinical trials. The combination of oral or nasogastric tube instillation of vancomycin $500 \mathrm{mg}$ every $6 \mathrm{~h}$, intravenous (IV) metronidazole $500 \mathrm{mg}$ every $6 \mathrm{~h}$, rectal instillation of $500 \mathrm{mg}$ of vancomycin every $6 \mathrm{~h}$ in $100 \mathrm{~mL}$ of normal saline and IV gamma globulin (IVIG) $0.3 \mathrm{~g} / \mathrm{kg}$ to $0.5 \mathrm{~g} / \mathrm{kg}$ (in either one or two doses) has been used in small studies or clinical experiences by treating physicians (61). Early consultation with surgery to determine if a colectomy is needed is recommended. Postsurgical intensive care unit (ICU) support is usually required. QID Four times daily; TID Three times daily

normal bowel flora (27), and it is presumed that metronidazole may have a similar effect, possibly accounting for relapses.

Prompt and effective therapy is essential to avoid disease progression. Should the patient develop nausea, vomiting, abdominal pain and distention, ileus or pancolitis with clinical toxicity, therapeutic approaches include intensive care unit 
admission, intravenous administration of metronidazole, intravenous immunoglobulin $0.3 \mathrm{~g} / \mathrm{kg}$ to $0.5 \mathrm{~g} / \mathrm{kg}(28-30)$, rectal instillation of vancomycin, and colectomy for threatened perforation, pancolitis and sepsis. Mortality in these circumstances is in the order of $30 \%$ to $40 \%$.

Additional alternative therapies, all with less clinical experience, include bacitracin, fucidin, rifampin, teicoplanin and rifaximin (last two not available in Canada) (31-34).

\section{UPCOMING NEW THERAPIES}

It is expected that new therapies will be forthcoming in the next two to four years with the aim of achieving greater than $90 \%$ response rates with a low rate of relapse. There are several novel therapies being examined.

\section{Tiacumicin B, OPT-80/PAR-101}

Tiacumicin B, OPT-80/PAR-101 (Optimer Pharmaceuticals, USA, and Par Pharmaceuticals, USA) is a nonabsorbed, macrocyclic antibiotic that has a partial lactone ring structure but is not a macrolide, and is eight- to 10 -fold more active than vancomycin against $\mathrm{C}$ difficile. It possesses modest activity against enterococci but otherwise is nearly inactive against the normal flora. It was previously shown to durably cure the hamster model of $\mathrm{C}$ difficile diarrheal disease (no relapse or death after treatment stops) (35). A phase 2A study of 45 patients has just been completed showing a high response rate followed by a low relapse rate (36), with relative sparing of components of the normal gut flora (37). The results were sufficiently promising such that a phase $2 \mathrm{~B} / 3 \mathrm{~A}$ study of 500 patients, comparing $200 \mathrm{mg}$ twice daily for 10 days and vancomycin $125 \mathrm{mg}$ four times daily for 10 days, is now underway.

\section{Tolevamer}

Tolevamer (Genzyme Corporation, USA) is a soluble binder of $\mathrm{C}$ difficile toxins $\mathrm{A}$ and $\mathrm{B}$. The objective of toxin binding is to neutralize toxins $\mathrm{A}$ and $\mathrm{B}$, and to cure or prevent disease by allowing the normal flora to recover over time. Toxin-binding therapy was shown to durably cure hamsters with CDAD in 2001 (38). A phase 2 study in 2002 to 2003 studied 287 patients in three groups. The $6 \mathrm{~g}$ per day of toxin-binding therapy resulted in a $79 \%$ response rate (noninferior to vancomycin) followed by a $7 \%$ recurrence rate, whereas a $91 \%$ response rate to vancomycin was followed by a $20 \%$ recurrence rate (39). Two large, phase 3 trials are underway to compare a $9 \mathrm{~g}$ daily dose of toxinbinding therapy to metronidazole or vancomycin.

\section{Other candidate therapies}

Other candidate therapies include ramoplanin, a lipoglycodepsipeptide (Oscient Pharmaceuticals, USA); rifaximin (Salix Pharmaceuticals, USA), a poorly absorbed rifamycin $(40,41)$; and nitazoxanide, an anticryptosporidia agent (Alinia, Romark Pharmaceuticals, USA). Immunobiological approaches that are in the early stages of development include vaccines (42), ingestion of nontoxigenic $\mathrm{C}$ difficile $(43,44)$ and ingestion of antibodies (45) that would bind elements of the toxin or adherence factors. Definitive clinical trials are required to determine the usefulness of these new treatments.

\section{CDAD-INDUCING ANTIBIOTICS}

Any antimicrobial that can suppress the normal microbial floral balance, particularly intestinal anaerobes, can induce CDAD. Exact risks are not available because the number of persons colonized is usually not determined, infectious inocula are variable, and because of varying determinants of disease, such as time of acquisition, host humoral antibody response (46), age, underlying disease and ecological effects of antibiotics. Nevertheless, it is generally appreciated that aminoglycosides, co-trimoxazole and intravenously administered vancomycin rarely induce CDAD. The main inducers are clindamycin, cephalosporins and amoxicillin or other beta-lactams. Quinolones, tetracyclines and probably macrolides can also be inducers. In the Quebec outbreak, the dominant pathogen was highly quinolone resistant, and it is suspected that the high use of quinolones in hospital and in community medicine was a factor. While there is a class effect by quinolones in selecting for $\mathrm{C}$ difficile disease, the risk may be higher with the 8-methoxy agents, gatifloxacin and moxifloxacin $(12,47)$. At present, antibiotic control in institutions should still be focused on restricting clindamycin and cephalosporins.

Narrow-spectrum agents are preferred in office practice (ie, penicillin $\mathrm{V}$ potassium is preferred over cephalosporins for the treatment of streptococcal pharyngitis; trimethoprimsulfamethoxazole [co-trimoxazole] still covers approximately $90 \%$ of outpatient strains of Escherichia coli for treatment of urinary tract infection and could reduce the overuse of quinolones; and cloxacillin remains a first-choice oral therapy of staphylococcal infections [methicillin-sensitive Staphylococcus aureus]). Pivampicillin, a highly absorbed (greater than 95\%) alternative to amoxicillin or ampicillin, is associated with less diarrhea and theoretically should be less likely to induce disease. It is not possible to completely avoid the induction of CDAD, but it is possible to use antibiotics so that the induction of CDAD is minimized. Limiting the duration of exposure (ie, shorter courses of therapy) to all agents is desirable.

\section{INFECTION CONTROL ISSUES}

Due to the high frequency of use of antimicrobials in the hospital population combined with a suboptimal physical plant and difficult practice conditions, CDAD is a universal infection control problem. Up to $30 \%$ of patients have been observed in hospital surveys to acquire $\mathrm{C}$ difficile in their stool over time. The spore persists in the environment for months, and endemicity in hospitals is perpetuated by the vicious cycle of diarrheal illness and environmental contamination. For this reason, the medical staff's prescribing habits have a major role in maintaining or, alternatively, in stopping this cycle. We have found that most patients have $10^{3}$ to $10^{4}$ spores/g of feces during and following treatment. Ideally, all patients on medical and surgical floors, where CDAD risk is highest, should have a bed-to-toilet ratio of 1:1 to limit transmission of nosocomial pathogens. However, the reality is that the majority of acute care beds in Canada have shared toilet facilities. Therefore, prudent antimicrobial use, patient personal hygiene, avoidance of shared toilet facilities with ill patients and health care worker adherence to the principles of standard practice (hand hygiene, and appropriate barrier precautions before and after all patient contacts) are cornerstones for the prevention of CDAD. Patients with diarrheal stools and incontinence are to be isolated and maintained on contact precautions. Handwashing with soap and water (because alcohol gel does not kill the spores) is recommended. However, widespread application of alcohol hand rubs has not been observed to increase CDAD rates (48). On wards with high rates of endemicity, hand hygiene by all patients should be taught and enforced. 


\section{WHAT DO WE DO ABOUT THE CHRONIC RELAPSING PATIENT?}

The most difficult clinical issue in the management of CDAD is what to do about the chronic relapsing patient. Generally, most patients respond to a repeat course of therapy with metronidazole or vancomycin, although subsequent recurrence rates remain high (20\% to 40\%). Quantitative cultures of the normal flora during CDAD show severe depletion of major genera of the normal flora before the initiation of therapy. There is no proof that probiotics, given as one, two or three organisms as a means of replenishing the normal microbiota, are efficacious in preventing relapse (49). There are also no data to support that probiotics prevented CDAD in the Quebec outbreak (M Miller and K Weiss, personal communication). However, probiotics have been found to be of some benefit in antibiotic-induced diarrhea. Saccharomyces boulardii has been shown to be modestly helpful in reducing the likelihood of relapse $(50,51)$. Tapering the dosage of vancomycin is commonly practised, although there are no controlled studies to examine the strategy; an observational substudy conducted during a probiotic study (51) supported tapering (Table 1). Fecal enemas to introduce the microflora of donors has been practised since 1958 (52,53) and is highly effective but aesthetically displeasing. In Calgary, from 1996 to 2006, 26 patients with chronic relapsing disease for longer than six months were treated with fecal enemas, with a greater than 95\% response rate (authors' unpublished observation). One investigator in Duluth, Minnesota, USA, used a nasogastric tube to deliver intestinal microbes (54); however, this approach runs the risk of colonizing the small bowel with coliforms. To simplify microfloral replacement, Tvede and Rask-Madsen (55) used a 10-microflora replacement cocktail for relapsing CDAD, given rectally. It is hoped that new therapies will reduce the incidence of recurrent disease. There is an urgent need to study the immunology and microbiology of relapsing CDAD patients and to investigate new therapies for this patient subset.

\section{SUMMARY}

CDAD is an antibiotic-induced infection that is common both in and out of hospital. It is hoped that more selective therapies will lead to less relapsing disease and that the new therapies will allow more therapeutic options. Combinations of new modalities should also be considered. Current control strategies
TABLE 1

Treatment of recurrent Clostridium difficile-associated diarrhea

- Re-treat for 10 days with previous effective regimen for symptom control.

- Start pulsed doses of vancomycin over three weeks (eg, $125 \mathrm{mg}$ to $500 \mathrm{mg}$ every three days for a total of seven doses) (56), or

start tapering doses of vancomycin over three to four weeks (eg, $125 \mathrm{mg}$ three times daily to two times daily to once daily) (56), stepping down by one capsule per week. A lower dose is possible with the intravenous solution given orally (eg, $62.5 \mathrm{mg}$ as a $1.25 \mathrm{~mL}$ solution once daily in the fourth week).

- No clear benefit of using probiotics has been shown, although probiotics have no observed adverse outcomes (49).

- Cholestyramine has not been shown to be effective (38).

- A modest benefit has been shown for Saccharomyces boulardii (51).

- Intravenous gamma globulin (57).

- Rifaximin or rifampin may be tried; there have been no randomized controlled trials for this indication. Rifaximin is available in many countries but not in Canada. Rifampin plus vancomycin has been used in one small set of patients for therapy (58); with the knowledge that vancomycin suppresses the normal bowel flora, including Bacteroides species, use of rifampin alone needs to be investigated.

- Microfloral replacement by various methods may be used $(54,59,60)$.

- Await new therapies with neutralization of toxins $A$ and $B$ or treatment with new, potentially more selective therapies.

Most cases of relapse are with the same strain, but in an environment where different $\mathrm{C}$ difficile spores are present, infection by a different strain is possible; generally, there is no difference in approach

include prudent antibiotic use both in and out of hospital, prompt screening of patients with antibiotic-induced diarrhea, attention to infection control practices, physical plant improvement when the opportunity arises and expeditious therapy. Periodic surveillance of strains should be considered on a local and nationwide basis to help physicians choose less inductive therapies for the treatment of infectious diseases.

CONFLICT OF INTEREST: TJL is the medical director of the Infection Prevention and Control Program, Calgary, Alberta, and is an investigator for Genzyme Corporation and Optimer Pharmaceuticals.

\section{REFERENCES}

1. Noren T, Akerlund T, Back E, et al. Molecular epidemiology of hospitalassociated and community-acquired Clostridium difficile infection in a Swedish county. J Clin Microbiol 2004;42:3635-43.

2. Miller MA, Hyland M, Ofner-Agostini M, Gourdeau M, Ishak M; Canadian Hospital Epidemiology Committee; Canadian Nosocomial Infection Surveillance Program. Morbidity, mortality, and healthcare burden of nosocomial Clostridium difficile-associated diarrhea in Canadian hospitals. Infect Control Hosp Epidemiol 2002;23:137-40.

3. McDonald LC, Owings M, Jernigan DB. Clostridium difficile infection in patients discharged from US short-stay hospitals, 1996-2003. Emerg Infect Dis 2006;12:409-15.

4. Health Protection Agency. Voluntary reporting of Clostridium difficile, England, Wales, and Northern Ireland: 2004. CDR Wkly 2005;15:1-3. <http://www.hpa.org.uk/cdr/archives/2005/cdr2005.pdf> (Version current at May 31, 2006)

5. Johnson S, Samore MH, Farrow KA, et al. Epidemics of diarrhea caused by a clindamycin-resistant strain of Clostridium difficile in four hospitals. N Engl J Med 1999;341:1645-51.

6. MacCannell D, Krulicki W, Ward L, et al. Clonal diversity of Clostridium difficile in response to a region-wide reduction in clindamycin utilization. CIDS/CHICA/CAMM 2004 Conjoint Conference. Calgary, April 29 to May 2, 2004.

7. Institut National de Santé Publique du Québec. Surveillance des diarrhées associées à Clostridium difficile au Québec. Résultats du 22 aout 2004 au 5

février 2005. < http://www.inspq.qc.ca/pdf/publications/370-ResultatsCDifficile22Aout2004-05Fevrier2005.pdf $>$ (Version current at May 31, 2006)

8. Loo VG, Poirier L, Miller MA, et al. A predominately clonal multiinstitutional outbreak of Clostridium difficile-associated diarrhea with high morbidity and mortality. N Engl J Med 2005;353;2442-9. (Erratum in 2006;354:2200)

9. Warny M, Pepin J, Fang A, et al. Toxin production by an emerging strain of Clostridium difficile associated with outbreaks of severe disease in North America and Europe. Lancet 2005;366:1079-84.

10. Pepin J, Valiquette L, Cossette B. Mortality attributable to nosocomial Clostridium difficile-associated disease during an epidemic caused by a hypervirulent strain in Quebec. CMAJ 2005;173:1037-42.

11. McDonald LC, Killgore GE, Thompson A, et al. An epidemic, toxin gene-variant strain of Clostridium difficile. N Engl J Med 2005;353:2433-41.

12. Debasi S, Vaessen N, Choudry A, van den Berg R, Kuijper E. Outbreak of Clostridium difficile PCR-ribotype 027 toxinotype III in Harderwijk, the Netherlands. Poster 1640. 16th European Congress of Clinical Microbiology and Infectious Diseases. Nice, France, April 1 to 4, 2006.

13. Eggertson L. Quebec strain of C. difficile in 7 provinces. CMAJ 2006;174:607-8.

14. MacCannell DR, Louie TJ, Gregson DB, et al. Molecular analysis of Clostridium difficile PCR ribotype 027 isolates from eastern and western Canada. J Clin Microbiol 2006;44:2147-52. 
15. Dial S, Alrasadi K, Manoukian C, Huang A, Menzies D. Risk of Clostridium difficile diarrhea among hospital inpatients prescribed proton pump inhibitors: Cohort and case-control studies. CMAJ 2004;171:33-8.

16. Al-Tureihi FI, Hassoun A, Wolf-Klein G, Isenberg H. Albumin, length of stay, and proton pump inhibitors: Key factors in Clostridium difficile-associated diarrhea in nursing home patients. J Am Med Dir Assoc 2005;6:105-8.

17. Dial S, Delaney JA, Barkun AN, Suissa S. Use of gastric acid-suppressive agents and the risk of community-acquired Clostridium difficile-associated disease. JAMA 2005;294:2989-95.

18. Snell H, Ramos M, Longo S, John M, Hussain Z. Performance of the TechLab C. DIFF CHEK-60 enzyme immunoassay (EIA) in combination with the C. difficile Tox A/B II EIA kit, the Triage C. difficile panel immunoassay, and a cytotoxin assay for diagnosis of Clostridium difficileassociated diarrhea. J Clin Microbiol 2004;42:4863-5.

19. O'Connor D, Hynes P, Cormican M, Collins E, Corbett-Feeney G, Cassidy M. Evaluation of methods for detection of toxins in specimens of feces submitted for diagnosis of Clostridium difficile-associated diarrhea. J Clin Microbiol 2001;39:2846-9.

20. Alfa MJ, Swan B, VanDekerkhove B, Pang P, Harding GK. The diagnosis of Clostridium difficile-associated diarrhea: Comparison of Triage C. difficile panel, EIA for Tox A/B and cytotoxin assays. Diagn Microbiol Infect Dis 2002;43:257-63.

21. Delmee M, Van Broeck J, Simon A, Janssens M, Avesani V. Laboratory diagnosis of Clostridium difficile-associated diarrhea: A plea for culture. J Med Microbiol 2005;54:187-91.

22. Bouza E, Pelaez T, Alonso R, Catalan P, Munoz P, Creixems MR. "Second-look" cytotoxicity: An evaluation of culture plus cytotoxin assay of Clostridium difficile isolates in the laboratory diagnosis of CDAD. J Hosp Infect 2001;48:233-7.

23. Vasa CV, Glatt AE. Effectiveness and appropriateness of empiric metronidazole for Clostridium difficile-associated diarrhea. Am J Gastroenterol 2003;98:354-8.

24. Bricker E, Garg R, Nelson R, Loza A, Novak T, Hansen J. Antibiotic treatment for Clostridium difficile-associated diarrhea in adults. Cochrane Database Syst Rev 2005;(1):CD004610.

25. Pepin J, Alary ME, Valiquette L, et al. Increasing risk of relapse after treatment of Clostridium difficile colitis in Quebec, Canada. Clin Infect Dis 2005;40:1591-7.

26. Fekety R, Silva J, Kauffman C, Buggy B, Deery HG. Treatment of antibioticassociated Clostridium difficile colitis with oral vancomycin: Comparison of two dosage regimens. Am J Med 1989;86:15-9.

27. Edlund C, Barkholt L, Olsson-Liljequist B, Nord CE. Effect of vancomycin on intestinal flora of patients who previously received antimicrobial therapy. Clin Infect Dis 1997;25:729-32.

28. Salcedo J, Keates S, Pothoulakis C, et al. Intravenous immunoglobulin therapy for severe Clostridium difficile colitis. Gut 1997;41:366-70.

29. Wilcox MH. Descriptive study of intravenous immunoglobulin for the treatment of recurrent Clostridium difficile diarrhoea. J Antimicrob Chemother 2004;53:882-4.

30. Kink JA, Williams JA. Antibodies to recombinant Clostridium difficile toxins $A$ and $B$ are an effective treatment and prevent relapse of $C$. difficileassociated disease in a hamster model of infection. Infect Immun 1998;66:2018-25.

31. Wullt M, Odenholt I. A double-blind randomized controlled trial of fusidic acid and metronidazole for treatment of an initial episode of Clostridium difficile-associated diarrhoea. J Antimicrob Chemother 2004;54:211-6.

32. Wenisch C, Parschalk B, Hasenhundl M, Hirschl AM, Graninger W. Comparison of vancomycin, teichoplanin, metronidazole, and fusidic acid for the treatment of Clostridium difficile-associated diarrhea. Clin Infect Dis 1996;22:813-8. (Erratum in 1996;23:423)

33. Dudley MN, McLaughlin JC, Carrington G, Frick J, Nightingale CH, Quintiliani R. Oral bacitracin vs vancomycin therapy for Clostridium difficileinduced diarrhea. A randomized double-blind trial. Arch Intern Med 1986;146:1101-4

34. de Lalla F, Nicolin R, Rinaldi E, et al. Prospective study of oral teichoplanin versus oral vancomycin for therapy of pseudomembranous colitis and Clostridium difficile-associated diarrhea. Antimicrob Agents Chemother 1992;36:2192-6.

35. Swanson RN, Hardy DJ, Shipkowitz NL, et al. In vitro and in vivo evaluation of tiacumicins B and $\mathrm{C}$ against Clostridium difficile. Antimicrob Agents Chemother 1991;35:1108-11.

36. Louie T, Miller M, Donskey C, et al. Safety, pharmacokinetics and outcomes of PAR-101 in healthy subjects and patients with Clostridium difficileassociated ciarrhea (CDAD). Poster LB2-29. 45th Interscience Conference on Antimicrobial Agents and Chemotherapy, American Society for Microbiology. Washington, December 16 to 19, 2005.

37. Louie TJ, Emery J, Krulicki W, Byrne B, Mah M. PAR-101 is selectively effective against $C$. difficile in vivo and has minimal effect on the anaerobic fecal flora. Poster LB2-30. 45th Interscience Conference on Antimicrobial
Agents and Chemotherapy, American Society for Microbiology. Washington, December 16 to 19, 2005.

38. Kurtz CB, Cannon EP, Brezzani A, et al. GT160-246, a toxin binding polymer for treatment of Clostridium difficile colitis. Antimicrob Agents Chemother 2001;45:2340-7.

39. Louie TJ, Peppe J, Watt CK, et al; Tolevamer study investigator group. Tolevamer, a novel nonantibiotic polymer, compared to vancomycin in the treatment of mild-moderately severe C. difficile-associated diarrhea. Clin Infect Dis 2006. (In press)

40. Testa R, Eftimiadi C, Sukkar GS, et al. A non-absorbable rifamycin for treatment of hepatic encephalopathy. Drugs Exp Clin Res 1985;11:387-92.

41. Kokkotou E, Mustafa N, O'Brien M, Pothoulakis C, Kelly CP. Rifaximin: A novel non-absorbed antibiotic therapy for Clostridium difficile-associated diarrhea. Poster B-35. 45th Interscience Conference on Antimicrobial Agents and Chemotherapy, American Society for Microbiology. Washington, December 16 to $19,2005$.

42. Giannasca PJ, Warny M. Active and passive immunization against Clostridium difficile diarrhea and colitis. Vaccine 2004;22:848-56.

43. Shim JK, Johnson S, Samore MH, Bliss DZ, Gerding DN. Primary symptomless colonisation by Clostridium difficile and decreased risk of subsequent diarrhoea. Lancet 1998;351:633-6.

44. Sambol SP, Cheknis A, Johnson S, Gerding DN. Prevention of recurrent Clostridium difficile (CD) disease in hamsters by colonization with nontoxigenic $\mathrm{CD}$ following treatment with vancomycin. Abstract B36. 45th Interscience Conference on Antimicrobial Agents and Chemotherapy, American Society for Microbiology. Washington, December 16 to $19,2005$.

45. Warny M, Fatimi A, Bostwick EF, et al. Bovine immunoglobulin concentrateClostridium difficile retains $\mathrm{C}$ difficile toxin neutralising activity after passage through the human stomach and small intestine. Gut 1999;44:212-7.

46. Kyne L, Warny M, Qamar A, Kelly CP. Association between antibody response to toxin $\mathrm{A}$ and protection against recurrent Clostridium difficile diarrhoea. Lancet 2001;357:189-93.

47. Pepin J, Saheb N, Coulombe MA, et al. Emergence of fluoroquinolones as the predominant risk factor for Clostridium difficile-associated diarrhea: A cohort study during an epidemic in Quebec. Clin Infect Dis 2005;41:1254-60.

48. Boyce JM, Ligi C, Kohan C, Dumigan D, Havill NL. Lack of association between the increased incidence of Clostridium difficile-associated disease and the increasing use of alcohol-based hand rubs. Infect Control Hosp Epidemiol 2006;27:479-83.

49. Dendukuri N, Costa V, McGregor M, Brophy JM. Probiotic therapy for the prevention and treatment of Clostridium difficile-associated diarrhea: A systematic review. CMAJ 2005;173:167-70. (Erratum in 2005;173:345)

50. McFarland LV, Surawicz CM, Greenberg RN, et al. A randomized placebocontrolled trial of Saccharomyces boulardii in combination with standard antibiotics for Clostridium difficile disease. JAMA 1994;271:1913-8. (Erratum in 1994;272:518)

51. Surawicz CM, McFarland LV, Greenberg RN, et al. The search for a better treatment for recurrent Clostridium difficile disease: Use of high-dose vancomycin combined with Saccharomyces boulardii. Clin Infect Dis 2000;31:1012-7.

52. EisemanB, Silen W, Bascom GS, Kauvar AI. Fecal enema as an adjunct in the treatment of pseudomembranous colitis. Surgery 1958;44:854-9.

53. Schwan A, Sjolin S, Trottestam U, Aronsson B. Relapsing Clostridium difficile enterocolitis cured by rectal infusion of homologous faeces. Lancet $1983 ; 2: 845$.

54. Aas J, Gessert CE, Bakken JS. Recurrent Clostridium difficile colitis: Case series involving 18 patients treated with donor stool administered via a nasogastric tube. Clin Infect Dis 2003;36:580-5

55. Tvede M, Rask-Madsen J. Bacteriotherapy for chronic relapsing Clostridium difficile diarrhoea in six patients. Lancet 1989;1:1156-60.

56. McFarland LV, Elmer GW, Surawicz CM. Breaking the cycle: treatment strategies for 163 cases of recurrent Clostridium difficile disease. Am J Gastroenterol 2002;97:1769-75.

57. Beales IL. Intravenous immunoglobulin for recurrent Clostridium difficile diarrhoea. Gut 2002;51:456.

58. Buggy BP, Fekety R, Silva J Jr. Therapy of relapsing Clostridium difficileassociated diarrhea and colitis with the combination of vancomycin and rifampin. J Clin Gastroenterol 1987;9:155-9.

59. Schwan A, Sjolin S, Trottestam U, Aronsson B. Relapsing Clostridium difficile enterocolitis cured by rectal infusion of normal faeces. Scand J Infect Dis $1984 ; 16: 211-5$.

60. Liacouras CA, Piccoli DA. Whole-bowel irrigation as an adjunct to the treatment of chronic, relapsing Clostridium difficile colitis. J Clin Gastroenterol 1996;22:186-9.

61. Olson MM, Shanholtzer CJ, Lee JT Jr, Gerding DN. Ten years of prospective Clostridium difficile-associated disease surveillance and treatment at the Minneapolis VA Medical Center, 1982-1991. Infect Control Hosp Epidemiol 1994;15:371-81. 


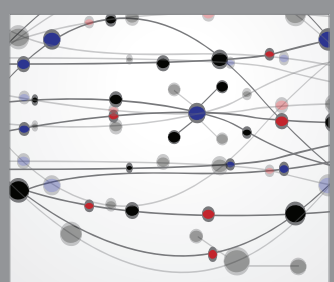

The Scientific World Journal
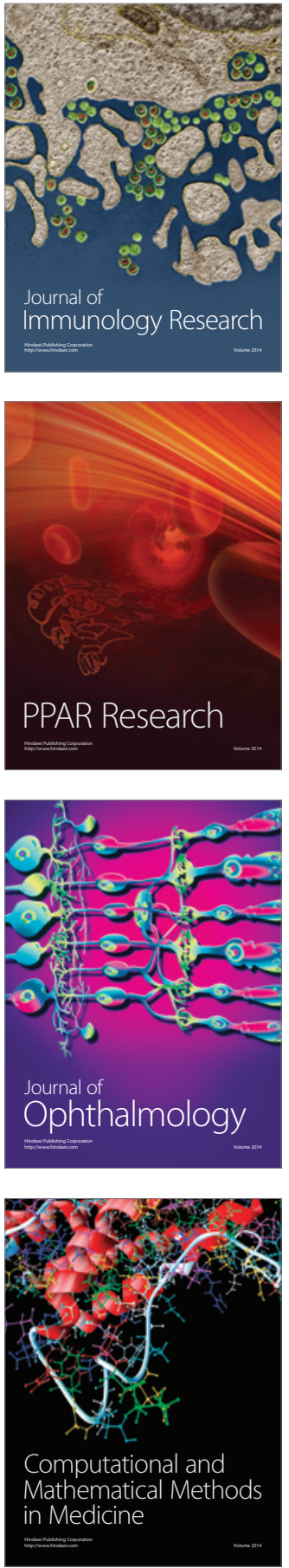

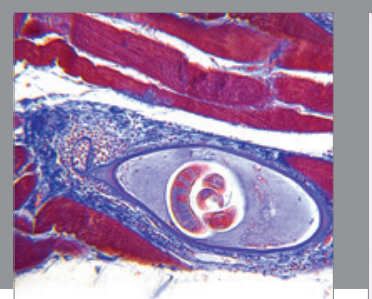

Gastroenterology Research and Practice

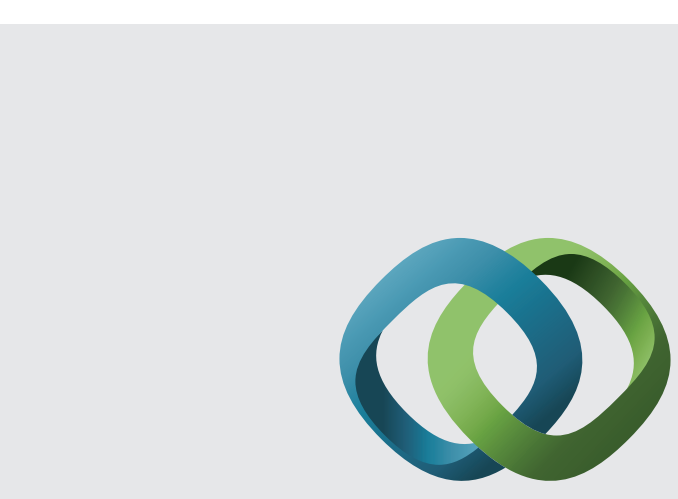

\section{Hindawi}

Submit your manuscripts at

http://www.hindawi.com
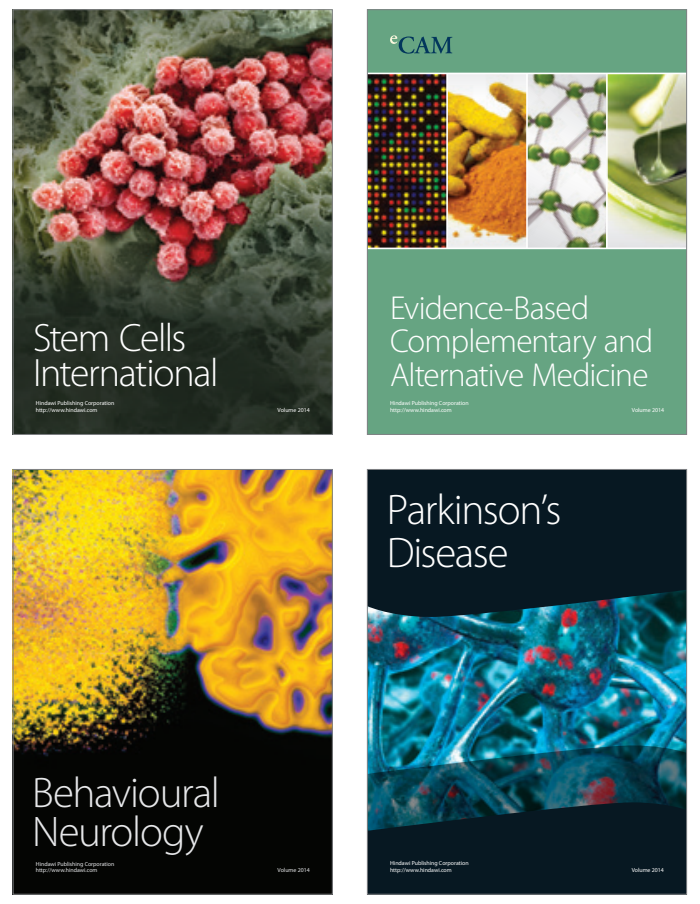
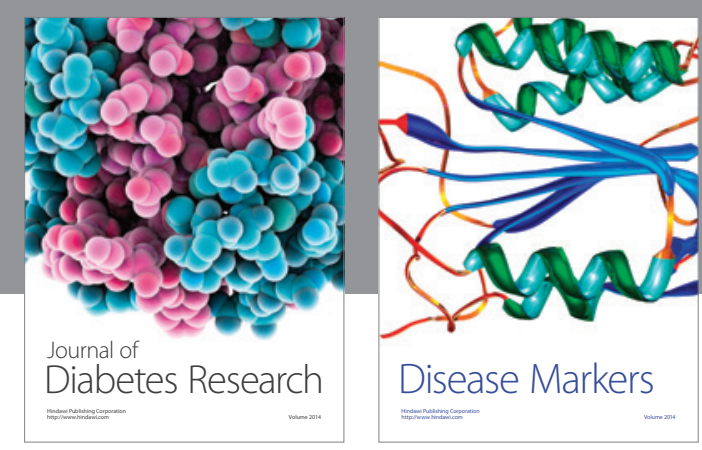

Disease Markers
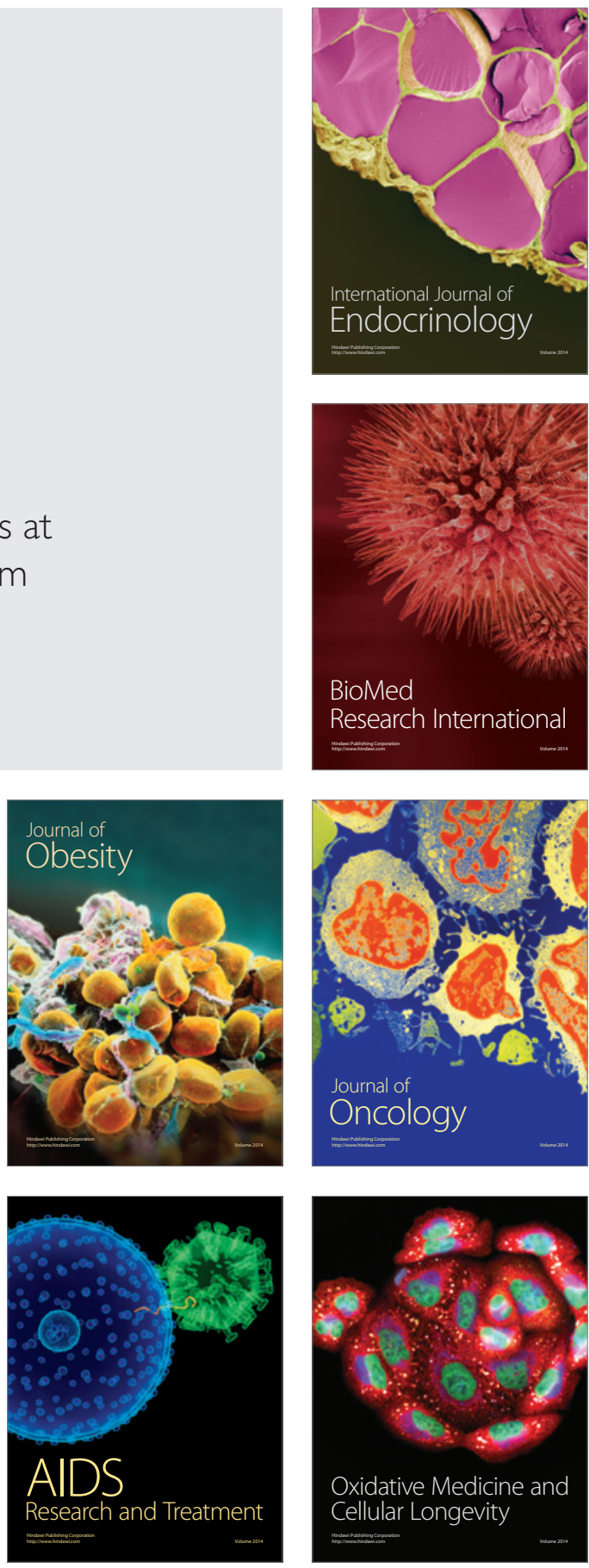